\title{
Context of Vignettes and Ethical Sensitivity in Decision-Making Among Undergraduate Business Studies Learners at University of Nairobi, Kenya
}

\author{
Prisca Mary Oluoch ${ }^{1}$, Paul Amollo Odundo ${ }^{1} \&$ John Kamau Mwangi ${ }^{1}$ \\ ${ }^{1}$ Department of Educational Communication \& Technology, University of Nairobi, Kenya \\ Correspondence: Prisca Mary Oluoch, Department of Educational Communication \& Technology, University of \\ Nairobi, Kenya. E-mail: prioluoch@gmail.com
}

Received: May 29, 2020

Accepted: July 2, $2020 \quad$ Online Published: July 22, 2020

doi:10.5539/jel.v9n4p151

URL: https://doi.org/10.5539/jel.v9n4p151

\begin{abstract}
Vignettes have been applied to train professionals in various fields, which has contributed to significant improvements in learning outcomes, ethical sensitivity and learners' ethical decision-making. At the University of Nairobi's Department of Educational Communication and Technology, most instructors have been slow to embrace experiential learning and inconsistent in applying vignettes to deliver business ethics lessons that emphasise ethical sensitivity in decision-making, with far reaching effects on the quality of graduates. This study responded to the information gap about the relationship between the use of vignettes and learners' ethical sensitivity in decision-making at the University of Nairobi. Cross-sectional survey design guided the research process, and primary data were sourced in 2018 from 116 learners. Both quantitative and qualitative analysis techniques were applied. Key results show that learners who agreed strongly that the context of vignettes influences ethical sensitivity in decision-making were about 3.9 times as likely to make ethically sensitive decisions as colleagues who disagreed strongly. Those who agreed that the context of vignettes influences ethical sensitivity in decision-making had about 2.3 times the odds of making ethically sensitive decisions as colleagues who indicted strong disagreement. This means that the more the learners appreciated that the context of vignettes influences ethical sensitivity in decision-making, the higher the chances of them making ethically sensitive decisions, and vice-versa. This brings to the fore the need for instructors to consistently apply the context of vignettes to deliver business ethics lessons to improve learners' ethical sensitivity and propensity to make ethical decisions. The study recommends that for practice, vignettes business contexts should be integrated in teacher training business studies ethics lessons.
\end{abstract}

Keywords: context vignettes, ethical, decision-making, business education, business ethics

\section{Introduction}

The University of Nairobi (UoN) is the largest institution of higher learning in Kenya, with 84,000 learners, 540 academic programmes and six constituent colleges (UoN, 2017). The College of Education and External Studies (CEES) specialises in the development of education sector's human resource, including teachers, managers and policy experts. CEES houses two schools, namely, the School of Education, and the School of Continuing and Distance Education. The former comprises four departments, one of which is the Department of Educational Communication and Technology (hereafter referred to as 'the Department'), where this study was conducted (UoN, 2017). Bachelor of Education (Arts) is one of the academic programmes offered by the Department. The programme, which encapsulates Business Studies as a subject, and Business Ethics, as a compulsory course unit, was designed to develop learners' ethical sensitivity and ethical decision-making skills in the professional realm, as well as enhance resilience to pressures involved in making ethical decisions at the workplace or the teaching-learning environment.

At the time of the study, 446 learners were enrolled for a Business Studies subject at the Department (UoN, 2018). Odundo and Gunga (2013) as well as Omwenga (2006) identify classical instruction as the model that has predominated learning at the UoN for over four decades. The model, which is characterised by systematic scripted lesson plans, lectures, presentations, notes and summative evaluations, is predominantly teacher-centered, which overlooks sensitivity in ethical decision-making during the teaching-learning process. This implies that learners 
are only passively involved in the learning process as recipients of information, a fact that limits creativity and impairs the development of essential professional skills (Petrina, 2004).

Instructional methods are pre-determined procedures through which instructors and learners interact to facilitate the learning process (Sarfo, 2007; Gray, Griffin \& Nasta, 2005; Petrina, 2004) for improved decision-making. Effectiveness of an instructional method is judged by the extent to which it captures learners' interests, optimises learning outcomes, and facilitates cognitive processing, storing and retrieval of information. All these draw extensively on sensitivity in ethical decision-making. Instructional methods are further evaluated by the extent to which each promotes learners' active participation in the learning process and limits dependency on instructors (Petrina, 2004; Hativa, 2000) to encourage reflection, dialogue and peer feedback for greater ethical sensitivity in decision-making.

Extant literature reveals a wide genre of instructional methods, which can be grouped under five models, including direct instruction, which is transmissive or classical instruction; indirect instruction, also known as transactive instruction; independent study; interactive instruction; as well as experiential or work-based learning (Petrina, 2004), all of which require sensitivity in ethical decision-making. Experiential learning is a unique model of instructional methods for developing the capacity of learners based on real life experiences, which are deeper and more complex than classical instructional methods such as, lectures. Harland (2014) argued that while the classical model transmits abstract information, which most learners struggle to put into perspective, experiential learning deploys practical experiences which learners can easily connect with to achieve mastery in ethical sensitivity and decision-making, and may improve choice of approach for effective and efficient management of professional development. In line with this thought, Petrina (2004) elaborates that experiential learning is about developing decision-making skills by enabling learners to reflect, discuss, share experiences, and apply such skills to tackle similar challenges requiring ethical sensitivity in decision-making. This suggests that experiential learning is a learner-centered model, under which learners are granted autonomy to actively drive the learning process by critically analysing content, engaging with peers and instructors about the content, and building consensus (Harland, 2014). Within the ambit of the business ethics course unit, experiential learning enables learners to understand and develop necessary skills for making sensitive ethical decisions from real life experiences for enhanced learner achievement in the teaching-learning process.

The experiential learning model deploys a wide spectrum of learning resources, including vignettes, which Kidwell and Valentine (2009), as well as Mazanec (2005) in their earlier studies, hold in high regard as influencers of learners' critical thinking and perceptions about real life experiences. More distinctively, Kidwell and Valentine (2009) elaborate that vignettes create a vital linkage between the learning process and learners' previous experiences in various facets of life, including work; while Mazanec (2005) observes that the deployment of vignettes in teaching sensitivity in business ethics is crucial for influencing learners' sensitivity in decision-making. Pan and Sparks (2011) view ethical sensitivity as an essential antecedent to ethical decision-making promoting effectiveness and efficiency in the use of instructional resources, methods and activities necessary for teaching-learning processes.

A review of pertinent literature reveals that vignettes have been applied to train professionals in various fields, including nursing, psychology and marketing (Allibaih \& Khan, 2015; Emanuel \& Cross, 2012). The cited studies have linked vignettes to significant improvements in learning outcomes, ethical sensitivity and learners' ability to make ethical decisions in work contexts. Similarly, Effelsberg, Solga and Gurt (2014) hold the view that the use of vignettes influences learners' ability to make ethical decisions, especially by enabling them to systematically and actively discuss ethical issues. Oluoch, Odundo, Mwangi and Oyier (2018), reiterate the importance of vignettes in learning, perceiving them as elemental instructional resources for developing learners' ethical sensitivity, in addition to preparing them for decision-making in professional contexts.

Despite the cited advantages about the use of vignettes and tendencies of ethical sensitivity in decision-making by learners, anecdotal information suggests that most instructors at the Department are slow to embrace experiential learning, and are inconsistent in applying vignettes to deliver business ethics lessons. Oluoch et al. (2018) have attributed the challenge to various factors, including instructors' insufficient use of experiential learning approaches and limited appreciation of how the use of vignettes in business ethics lessons influences learners' ethical sensitivity in decision-making proclivities. There is no doubt that these challenges have undermined the effectiveness of business ethics course in preparing learners to function effectively in their work locales (Oluoch, Odundo, \& Mwangi, 2019).

Even though vignettes have been used to train professionals in various fields, in education, there is remarkable paucity of empirical literature focusing on the application of vignettes and the influence on learners' ethical 
sensitivity in decision-making (Oluoch et al., 2018; 2019). More specifically, no study has examined how the use of vignettes to deliver the business ethics course unit influenced ethical sensitivity in decision-making among undergraduate learners at the Department. The resultant dearth of information has contributed to delay in pedagogical reforms at the institution. This study responded to the information gap by assessing the influence of vignettes on ethical sensitivity in decision-making among business education undergraduate learners at the UoN.

The study covered five aspects of vignettes, namely the context, content, types, construction and utilization; however, this article delves into the relationship between the context of vignettes and ethical sensitivity in decision-making among the said learners. The study sought to generate information that would synergize pedagogical reforms at the Department, in addition to motivating further relevant academic research in Kenya and elsewhere.

\section{Literature Review}

Developing teachers, institutional managers and leaders with a high level of ethical sensitivity in any sector starts the provision of the right professional training, using correct instructional methods (Pont, Nuschew, \& Moorman, 2008). There is a need to prepare leaders who are both knowledgeable and practically effective. Theoretical or academic work is complemented to a greater or lesser degree by experiential learning, problem-based approaches as well as experience. Vignettes are instructional resources that pre-expose learners to real life experiences in order to develop their ethical decision-making skills (Kidwell \& Valentine, 2009; Davis, DeZoort, \& Kopp, 2006). In the ambit of business ethics course unit, vignettes subject learners to practical ethical dilemmas that reflect challenges experienced in teaching and management of educational institutions. As noted by Guzak and Hargrove (2011), an effective instructional method should enable learners to develop positive values that promote ethical sensitivity in decision-making in all positions of responsibility. Literature on business education units reveals (Woods, 2014) five organizational contexts from where vignettes can be developed to support the training of future duty holders, including structural, operational, financial, human resource and marketing.

The structural context consists of Business course units that make decisions for safeguarding or furthering organizational interests, especially ethically sensitive teaching-learning processes. Each structure influences ethical decision-making differently for improved learner achievement. A few empirical studies have examined the relationship between the use of structural context vignettes and learners'/employees' ethical decision-making. For example, Oluoch et al. (2019) reported that $87.3 \%$ of the learners contacted affirmed that structural context vignettes influenced their ethical decision-making tendencies; while Van Summeren (2018) established that employees' ethical decision-making was influenced by sensitization using structural context vignettes, which should be embraced at the professional training level. Van Summeren (2018) explained that the use of such vignettes enabled employees to understand organizational ethical policies guiding various aspects, including financial, human resource and marketing management practices. Similarly, structural vignettes enable teacher trainees to bridge the gap between theory and practice for transfer of learning about policies and how they apply in practice in finance, marketing or human resources management.

In an earlier study, Butterfield, Treviño and Weaver (2000) observed that employees' propensity to make ethical decisions is a function of how often employees are informed about organizational ethical policies governing structural functions. On his part, Detert, Treviño and Sweitzer (2008) argued that the use of vignettes to disseminate information on organizational structural functions is essential for enhancing learners' ethical sensitivity in decision-making skills. The relationship between the use of structural context vignettes and ethical sensitivity in decision-making among learners also features in the study by McNamara, Smith and Murphy-Hill (2018), which reported lack of a significant difference between learners instructed using structural context such as code of ethics and control group, in terms of conformance to a standard code for making sensitive ethical decisions.

The operational context consists of functions that contribute to the achievement of organizational purpose, including planning, organizing, directing and controlling activities related to core mandate and ethically sensitive decisions which arise. As all operational functions involve ethically sensitive decision-making, Effelsberg et al. (2014) observed that vignettes inculcate positive attitudes and values that are essential for ethical decision-making within the operational context of the individual. Despite this, few studies have assessed the relationship between the use of operational context vignettes in training learners' ethical sensitivity in decision-making. Those that have, only report some basic descriptive findings. For example, Oluoch et al. (2019) found that $89.7 \%$ of the learners affirmed that the use of operational context vignettes influenced ethical sensitivity in decision-making predispositions.

The financial context comprises functions aimed at optimising organizational revenues and expenditures (Hill, 
2019) requiring prudent decision-making, which should be ethically sensitive. Vignettes are valuable instructional resources for developing learners into teachers of finance and financial managers with a sense of ethical responsibility. The use of vignettes is effective for sensitising learners about ethical aspects of institutional financial management. This implicitly suggests that the use of financial context vignettes and learners' ethical sensitivity in decision-making might be causally connected (Racelis, 2015) such that, trainees who are unable to perceive ethical issues where they exist may recommend inappropriate actions and vice-versa.

Human resource management is a set of skills that entails making ethically sensitive decisions to optimise workers' productivity, which determines learning achievement during the teaching-learning process. Vignettes have been found to be important instructional resources for developing the capacity of learners to become more effective in making ethical decisions concerning human resource issues. For example, Marques and Azevedo-Pereira (2009) implicitly suggest that training learners using human resource context vignettes is essential for improving ethical sensitivity in decision-making practices. Similarly, in Oluoch et al. (2019), 87.2\% of the learners affirmed that the use of human resource context vignettes led to the tendency to make ethically sensitive decisions. The findings emphasised that ethical sensitivity in decision-making would enhance teacher trainee practice of teaching and learning for better achievement.

Lastly, training of business ethics involves exposing learners to issues in marketing context using appropriate vignettes so as to improve ethical sensitivity in decision-making skills for improved class management and learning. As noted by Barczyk and Duncan (2012), training institutions have a moral obligation to design instructional methods and resources that enhance learners' ethical sensitivity and ethical decision-making skills. Guzak and Hargrove (2011) describe vignettes as essential instructional methods and resources for developing learners' sensitivity in decision-making on various aspects of marketing for enhanced performance and instilling higher moral values. More explicitly, Oluoch et al. (2019) indicated that $87.2 \%$ of the learners affirmed that marketing context vignettes influenced ethical sensitivity in decision-making practices concerning various aspects of marketing. This, in turn, facilitates mastery of concepts and values clarification for efficient teaching-learning processes.

The study is anchored on the Experiential Learning Theory (ELT) to explain the process of human learning through experience (Kolb \& Kolb, 2017; McLeod, 2017). Learning, in this context, is explained as a process of creating new knowledge by transforming experience from problems to decisions. The Theory consists of six propositions on human learning, viz. learning is a process and not an outcome; learning is a continuous process grounded on experience; learning requires resolution of conflicts between dialectically opposed modes of adaptation to the world; learning is a holistic process of adaptation; learning results from synergistic transactions between the learner and the environment; and learning is the process of creating knowledge (Manolis, Burns, Assudani, \& Chinta, 2012). To address the uniqueness of human learning in the teaching-learning of Business Ethics course unit, sensitivity in decision-making is critical in capturing the imagination of the learner for better outcomes.

The Theory encapsulates two interdependent concepts, namely, a four-stage cycle of learning and learning styles, which jointly enhance effectiveness in explaining experiential learning anchored on the ability of the teacher to choose sensitive and learner-appropriate methods and resources for better attainment. The four-stage learning cycle postulates that experiential learning occurs when learners progress through a cycle of four stages, including a concrete experience (CE) or encounter with a new situation; and reflective observation (RO) of the new situation, focusing on its consistency with past experiences. This culminates in abstract conceptualization (AC) and generalisations or conclusions, which entail active reflection, intended to generate new ideas or modify existing ones. Active Experimentation (AE) or testing is the last stage in the learning cycle. It entails application and modification of the new experience (Kolb \& Kolb, 2017; McLeod, 2017), all of which rely on sensitivity in decision-making at every stage.

Experiential learning cycle integrates experience, reflection, conceptualisation and action, which implies that the Theory perceives learning as an integrated process, revolving around the four stages, all being mutually supportive (McLeod, 2017). Further learning is understood to be an ongoing process, and not a one-off activity with a definite end of single outcome. Even though experiential learning may begin at any stage of the cycle and follow the subsequent stages to a logical conclusion, effective learning can only occur when a learner is able to execute all the four stages of the model. This, suggests that no one stage of the cycle can fulfill experiential learning on its own (Kolb \& Kolb, 2017). Further, an experiential learning process is spiral one, which helps students transform their knowledge into skills, rather than a linear that only helps learners acquire knowledge. Whereas the linear model conditions learners to become passive recipients of information, the Theory prepares learners to become active participants in the learning process by posing and answering questions, engaging in 
critical reflective thinking and making informed judgments (Kolb \& Kolb, 2017).

The Experiential Learning Model sets out four learning styles, based on the experiential learning cycle; which vary depending on the cognitive abilities of individual learners, as well as interactions between learners and their social environments (McLeod, 2017). Besides environmental factors, the choice of learning styles is determined by two pairs of variables, which the ELT describes as experiential learning style axes (Kolb \& Kolb, 2017; McLeod, 2017). Figure 1 shows the learning styles as espoused by the theory. They include diverging, assimilating, concrete experience and accommodating. Notably, the style adopted by instructors and learners is determined by the processing continuum, which shows how learners approach learning tasks, and the perception continuum, indicating learners' emotional response to experiential learning processes.

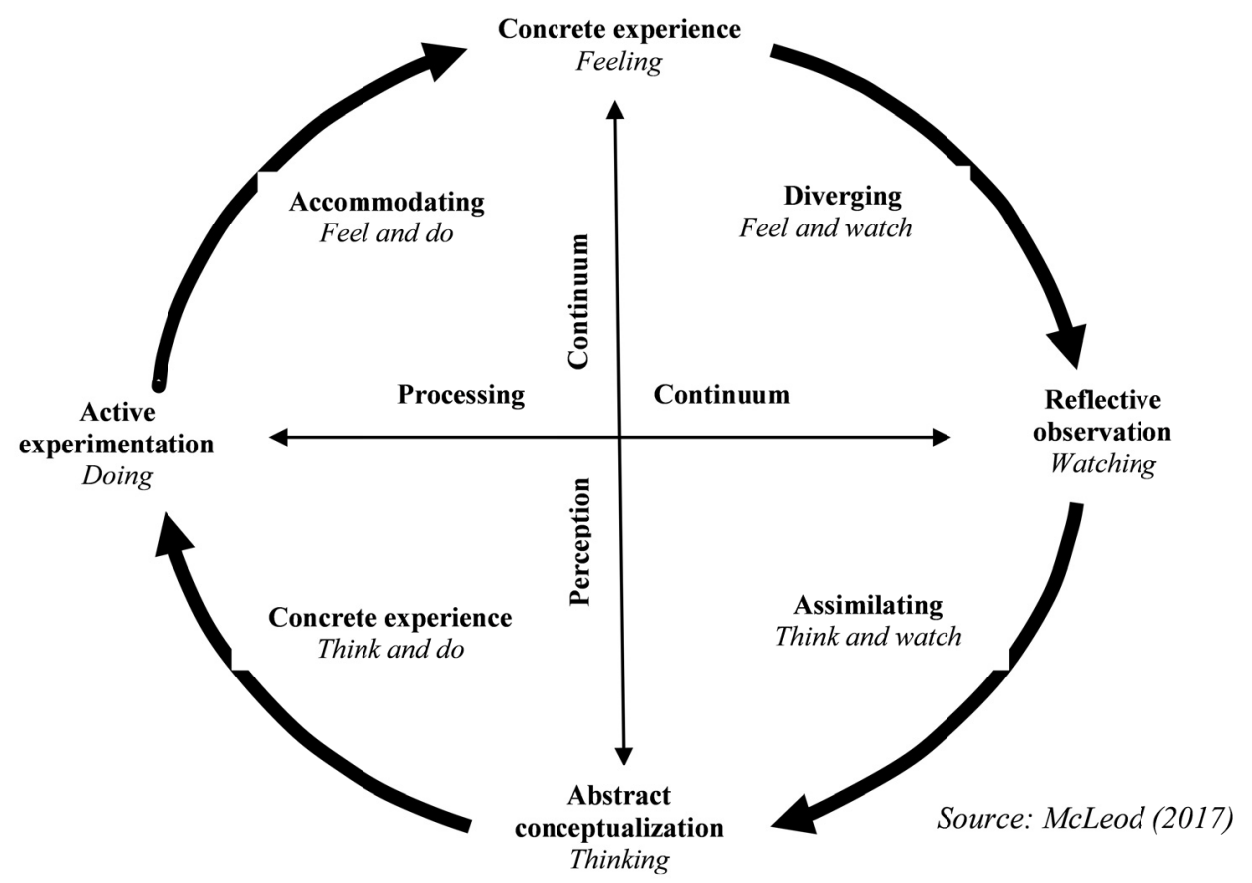

Figure 1. Experiential learning styles and learning axes (McLeod, 2017)

Although experiencing, reflecting, conceptualising and experimenting appear to be independent, they are mutually inter-connected. Kolb and Kolb (2017) believe that learners cannot perform both actions on a single axis at the same time. For example, a learner cannot simultaneously engage in thinking and feeling; but can amalgamate actions inherent in two adjacent modes. The theory is relevant for this study because it explains how experiential learning occurs, by keeping learners in touch with the reality being studied, which makes them different from those who only read or write about reality (Kolb \& Kolb, 2017). As observed by March (2010), vignettes promote experiential learning by exposing learners to real-life experiences, which develop their ethical sensitivity in decision-making skills.

The process of linking vignettes with professional experiences requires learners to follow the four stages of experiential learning cycle. The use of vignettes to subject learners to real-life ethical dilemmas is essential for helping them to learn from experience, which affirms that learning occurs when experience is transformed into knowledge. How well learners transform their experiences into knowledge depends on the extent to which the business ethics course unit is aligned to the experiential learning cycle, as well as the learning styles adopted by learners and instructors.

The study examined how the context of vignettes influences ethical sensitivity in decision-making among the undergraduate learners. In this regard, ethical decision-making was set as the dependent variable, with only two possible outcomes: ethically sensitive decisions or ethically insensitive decisions. The conceptual framework presented in Figure 2, hypothesises that the context of vignettes is likely to influence learners' ethical sensitivity in decision-making. 


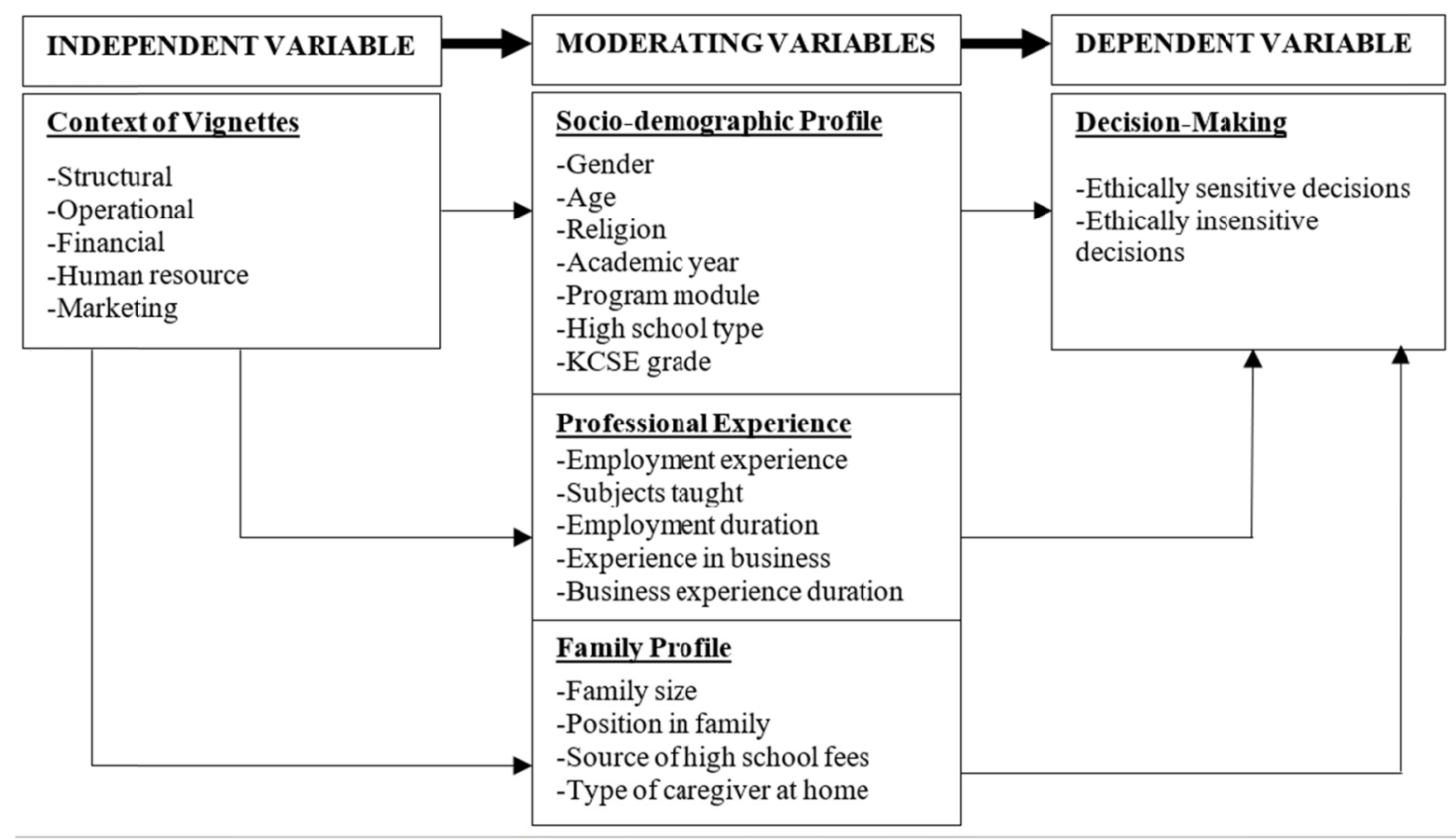

Figure 2. Hypothesized relationship between the context of vignettes and ethical sensitivity in decision-making

The conceptual framework suggests that the context of vignettes influences learners' ethical sensitivity in decision-making, through three sets of moderating factors, broadly grouped as learners' socio-demographic profile, professional experience and family profile. Each context of vignettes was transformed into a perception statement, which was measured using a five-point scale, calibrated as 'agree strongly', 'agree', 'undecided', 'disagree' and 'disagree strongly'. Participants were requested to indicate their perceptions about each statement. The outcome was aggregated to form the independent variable, viz. the context of vignettes.

\section{Methodology}

The approaches, design and methods used in this study were based on two philosophical schools of thought, namely positivism and constructivism, each with a unique set of assumptions about reality (ontology), knowledge about the reality (epistemology), and particular ways of knowing the reality (methodology). Details are explained in these publications: Wong (2014); Ashley and Orenstein (2005); as well as Easterby-Smith, Thorpe and Lowe (1991), among others. Based on positivist and constructivist principles, a mixed method approach was applied in sourcing, processing and analysing data in order to be able to comprehensively respond to the research question with both numbers and stories. The quantitative approach involved formulating and testing null hypotheses; while the qualitative approach captured open-ended views about the connection between context of vignettes and ethical sensitivity in decision making. This was captured through four focus group discussions (FGDs) with learners, and three key informant interviews (KIIs) with instructors. The survey questionnaire and interview schedule are attached in the Appendix.

Cross-sectional survey design was applied to guide the research process. The design was chosen because of its ability to source both quantitative and qualitative information, cost-effectiveness, ability to minimise vulnerability to confounding factors by sourcing data at a single point in time, as well as ability to generate a wide range of information using various measurement scales, including interval, ratio, nominal and ordinal (Kothari, 2010; Rindfleisch, Malter, Ganesan, \& Moorman, 2008; Bryman \& Cramer, 1998).

The study targeted third- and fourth-year Bachelor of Education learners taking Business studies course at the UoN, as well as instructors of business studies course at the same institution. Information obtained from the Department indicated that there were 219 such learners, including 107 (48.9\%) in the third-year and 112 (51.1\%) in the fourth-year. The sample size was computed using Cochran's formula (Cochran, 1963).

$$
n i=\frac{Z^{2} p q}{d^{2}}=\frac{1.96^{2} \times 0.489 \times 0.511}{0.05^{2}}=383.97
$$


Where: $n_{i}=$ sample size, $Z=$ confidence level: $1.96, p=$ proportion of learners in the third-year: 0.489 and $q=$ proportion learners in the fourth-year (1-p): 0.511. The output was then adjusted for design effects using the correction factor indicated in formula $2:-$

$$
n f=\frac{n i}{1+\frac{n i}{N i}}=\frac{383.97}{1+\frac{383.97}{219}}=139.46
$$

Where $n f=$ sample size correction factor, $n_{i}=$ computed sample size: $383.97, N_{i}=$ population: 219 . The correction process obtained a sample size of 139 learners. The sample size was divided proportionately between the two strata based on the population distribution, using formula 3: -

$$
n_{o}=f * s N_{o}
$$

Where $n_{o}=$ stratum sample size; $f=$ the sampling fraction $\left(n_{i} / N_{i}\right)$ and $s N_{o}=$ the stratum population (Kozak \& Zieli'nski, 2005). The quotient of computed sample size $\left(n_{i}\right)$ and the target population $\left(N_{i}\right)$ yielded a sampling fraction $(f)$ of 0.6368 . Using the sampling fraction, the computation yielded proportionate samples of 68 thirdand 71 fourth-year learners. Stratified random and purposive sampling procedures were applied to sample learners. Primary data were sourced using three types of tools namely, a self-administered questionnaire for learners, an FGD guide also for learners, and a KII guide for instructors. The tools and data sourcing approaches were pilot-tested between February and March, 2018 on second-year learners at the Department.

Both quantitative and qualitative techniques were applied to process and analyse the data. Quantitative analysis was performed using various techniques, including cross-tabulations with Chi-square $\left(\chi^{2}\right)$ statistic, Spearman's Rank Correlation Coefficient, and binary logistic regression analysis (Wuensch, 2006; Myers \& Well, 2003; Nachmias \& Nachmias, 1996). Binary logistic regression was applied to determine influence of the context of vignettes on learners' ethical decision-making. Under the model, the predicted variable takes the value 1 with a probability of success represented by $\theta$, or the value 0 with probability of failure represented by $1-\theta$. In this study, the dependent variable was ethical decision-making, with two possible outcomes, viz. ethically sensitive decisions or ethically insensitive decisions. The model is expressed as indicated in formula (4): -

$$
\operatorname{Logit}[\theta(Y)]=\log \left[\frac{\theta(Y)}{1-\theta(Y)}\right]=\alpha+\beta_{1} X_{1}+\beta_{2} X_{2}+\beta_{3} X_{3} \ldots+\beta_{i} X_{i}+\varepsilon_{i}
$$

Where $Y=$ the predicted variable, in this case, ethical decision-making; $\theta(Y)=$ the probability of a particular learner making an ethically sensitive decision; $1-\theta(Y)=$ the probability of a particular learner making an ethically insensitive decision; $\alpha=$ constant term of the equation; $\beta_{1}, \beta_{2} \ldots \beta_{i}=$ regression coefficients associated with independent variables; $X_{1}, X_{2} \ldots X_{i}=$ independent variables and $\varepsilon_{i}=$ the error term (Wuensch, 2006). Even though the analysis yielded various outputs, this article focused on $\beta$ coefficients and Odds Ratios (OR). The Statistical Package for Social Sciences and Microsoft Excel packages were applied in quantitative analysis. Qualitative data were processed and analysed following the three steps prescribed by Best and Khan (2004), namely organization, description and interpretation of data to explain the findings, and put emerging patterns into an analytical framework thus communicating the essence of what the data had revealed (Creswell, 2013) about the perceptions of relationship between vignette context and ethical sensitivity for decision making among the teacher trainees. The study was conducted in accordance with ethical principles of social science research, including respect for participants' rights to self-determination, voluntary participation and confidentiality (Dench, Iphofen \& Huws, 2004) besides receiving the necessary authority from the regulatory bodies.

\section{Results}

The results have been organized under four sub-sections, including univariate analysis of ethical sensitivity in decision-making; bivariate analysis of learners' background profile vis-à-vis ethical sensitivity in decision-making; bivariate analysis of the context of vignettes in relation to ethical sensitivity in decision-making; as well as multivariate analysis of the context of vignettes and ethical sensitivity in decision-making.

\subsection{Univariate Analysis of Ethical Sensitivity Decision-Making}

Learners were requested to read the hypothetical vignette presented below and make the most appropriate decision.

You and Lisa are Business Education teachers at Kitenge High School, a mid-sized boys' boarding school. Your department has recently completed setting end-of-term examinations and the head of your department has handed it to you, with the request that you submit it to the examination office. You and Lisa are working late that night when you receive a call from the Principal, who asks you to immediately forward 
him a copy of the draft Business Education examination. When you locate the copy, you discover that your head of department had sealed it and written "Final Copy, Confidential" on the envelope. Your head of department is out of the country attending a seminar and you know it would be impossible to locate him for consultation. The Principal has a son in your class, who is always top of his class. How would you handle the Principal's request?

The purpose of the task was to determine the proportion of learners whose decisions would show signs of adherence to the principles underlying ethical sensitivity in decision-making, including taking ethical responsibility, acting with professionalism, maintaining confidentiality, upholding honesty and showing respect for legitimate authority (Weiss, 2014; Carroll, 1990). The results presented in Table 1 show that of the 116 learners, $24(20.7 \%)$ demonstrated ethical responsibility in their decisions, while $34(29.3 \%)$ acted with professionalism.

Table 1. Proportion of learners' adhering to ethical sensitivity in decision-making principles

\begin{tabular}{lllllll}
\hline Principles guiding ethical & Yes & \multicolumn{3}{c}{ No } & \multicolumn{3}{l}{ Total } \\
\cline { 2 - 7 } decision-making & Frequency & Percent & Frequency & Percent & Frequency & Percent \\
\hline Taking ethical responsibility & 24 & 20.7 & 92 & 79.3 & 116 & 100.0 \\
Acting with professionalism & 34 & 29.3 & 82 & 70.7 & 116 & 100.0 \\
Maintaining confidentiality & 51 & 44.0 & 65 & 56.0 & 116 & 100.0 \\
Upholding honesty & 14 & 12.1 & 102 & 87.9 & 116 & 100.0 \\
Showing respect for authority & 26 & 22.4 & 90 & 77.6 & 116 & 100.0 \\
\hline
\end{tabular}

In addition, $51(44.0 \%)$ learners-maintained confidentiality, 14 (12.1\%) demonstrated honesty, while 26 (22.4\%) showed respect for legitimate authority. Overall, most learners, 51(44.0) maintained confidentiality; followed by those who acted professionally, 34 (29.3\%); while the least proportion of learners, 14 (12.1\%), ensured honesty. The results in Table 1 were aggregated to determine the proportion of learners who were ethically sensitive and those ethically insensitive in their decisions. In this regard, the analysis revealed that $30(25.9 \%)$ learners made ethically sensitive decisions, while 86 (74.1\%) exhibited ethical insensitivity in their decisions.

\subsection{Bivariate Analysis of Ethical Sensitivity in Decision-Making and Learners' Profile}

The learners included $59(50.9 \%)$ males and 57 (49.1\%) females, as indicated in Table 2. In relation to ethical sensitivity in decision-making, among those who were ethically sensitive $(\mathrm{n}=30), 17(56.7 \%)$ were females and $13(43.3 \%)$ were males. Those who were ethically insensitive consisted of $46(53.5 \%)$ males and $40(46.5 \%)$ females. The analysis revealed lack of a significant association between learners' gender and ethical sensitivity in decision-making $\left(\chi^{2}=0.556, \mathrm{df}=1 \& \rho\right.$-value $\left.=0.456\right)$; which, suggests that the decisions made by male and female learners were homogenous in terms of the ethical sensitivity. 
Table 2. Learners' social attributes and ethical sensitivity in decision-making principles

\begin{tabular}{|c|c|c|c|c|c|c|c|c|c|}
\hline \multirow{3}{*}{$\begin{array}{l}\text { Learners' socio-demographic } \\
\text { attributes }\end{array}$} & \multicolumn{6}{|c|}{ Ethical Sensitivity in Decision-Making } & \multirow{2}{*}{\multicolumn{3}{|c|}{ Chi square results }} \\
\hline & \multicolumn{2}{|c|}{ Ethically sensitive } & \multicolumn{2}{|c|}{ Ethically insensitive } & \multicolumn{2}{|l|}{ Total } & & & \\
\hline & Freq & Percent & Freq & Percent & Freq & Percent & $\chi^{2}$ & $d f$ & $\rho$-value \\
\hline \multicolumn{10}{|l|}{ Gender } \\
\hline Male & 13 & 43.3 & 46 & 53.5 & 59 & 50.9 & & & \\
\hline Female & 17 & 56.7 & 40 & 46.5 & 57 & 49.1 & 0.556 & 1 & 0.456 \\
\hline Total & 30 & 100.0 & 86 & 100.0 & 116 & 100.0 & & & \\
\hline \multicolumn{10}{|l|}{ Age } \\
\hline$<23$ years & 20 & 66.7 & 53 & 61.6 & 73 & 62.9 & & & \\
\hline $23-25$ years & 7 & 23.3 & 33 & 38.4 & 40 & 34.5 & 10.148 & 2 & $0.006^{* * *}$ \\
\hline 26 years + & 3 & 10.0 & 0 & 0.0 & 3 & 2.6 & & & \\
\hline Total & 30 & 100.0 & 86 & 100.0 & 116 & 100.0 & & & \\
\hline \multicolumn{10}{|l|}{ Religion } \\
\hline Christian & 29 & 96.7 & 84 & 97.7 & 113 & 97.4 & & & \\
\hline Muslim & 1 & 3.3 & 2 & 2.3 & 3 & 2.6 & 0.000 & 1 & 1.000 \\
\hline Total & 30 & 100.0 & 86 & 100.0 & 116 & 100.0 & & & \\
\hline \multicolumn{10}{|l|}{ Academic year } \\
\hline Third year & 18 & 60.0 & 73 & 84.9 & 91 & 78.4 & & & \\
\hline Fourth year & 12 & 40.0 & 13 & 15.1 & 25 & 21.6 & 6.740 & 1 & $0.009^{* * *}$ \\
\hline Total & 30 & 100.0 & 86 & 100.0 & 116 & 100.0 & & & \\
\hline \multicolumn{10}{|l|}{ Program module } \\
\hline Module 1 & 23 & 76.7 & 82 & 95.3 & 105 & 90.5 & & & \\
\hline Module 2 & 7 & 23.3 & 4 & 4.7 & 11 & 9.5 & 6.998 & 1 & $0.008^{* * *}$ \\
\hline Total & 30 & 100.0 & 86 & 100.0 & 116 & 100.0 & & & \\
\hline \multicolumn{10}{|l|}{ High school type } \\
\hline Mixed day & 2 & 6.7 & 12 & 14.0 & 14 & 12.1 & & & \\
\hline Mixed boarding & 3 & 10.0 & 9 & 10.5 & 12 & 10.3 & & & \\
\hline Boys boarding & 11 & 36.7 & 33 & 38.4 & 44 & 37.9 & 1.502 & 3 & 0.682 \\
\hline Girls' boarding & 14 & 46.7 & 32 & 37.2 & 46 & 39.7 & & & \\
\hline Total & 30 & 100.0 & 86 & 100.0 & 116 & 100.0 & & & \\
\hline \multicolumn{10}{|l|}{ KCSE grade } \\
\hline A- & 0 & 0.0 & 7 & 8.1 & 7 & 6.0 & & & \\
\hline $\mathrm{B}^{+}$ & 11 & 36.7 & 10 & 11.6 & 21 & 18.1 & & & \\
\hline B & 9 & 30.0 & 17 & 19.8 & 26 & 22.4 & & & \\
\hline B- & 10 & 33.3 & 51 & 59.3 & 61 & 52.6 & 14.384 & 4 & $0.006^{* * *}$ \\
\hline $\mathrm{C}+$ & 0 & 0.0 & 1 & 1.2 & 1 & 0.9 & & & \\
\hline Total & 30 & 100.0 & 86 & 100.0 & 116 & 100.0 & & & \\
\hline
\end{tabular}

Note. ${ }^{*}, * * * * *$ show significance at $\rho<0.1, \rho<0.05$ and $\rho<0.01$ error margins, respectively.

The results in Table 2 show that $73(61.6 \%)$ learners were aged below 23 years, while $40(34.5 \%)$ were in the 23-25 years aged bracket. Among those who were ethically sensitive $(n=30), 20(66.7 \%)$ were aged below 23 years, while $7(23.3 \%)$ were in the $23-25$ years bracket. Those who were ethically insensitive $(n=86)$, included $53(61.6 \%)$ learners aged below 23 years, and $33(38.4 \%)$ in the $23-25$ years category. The analysis revealed a significant association between learners' age and ethical sensitivity in decision-making $\left(\chi^{2}=10.148, \mathrm{df}=2\right.$ \& $\rho$-value $=0.006)$. Table 2 further indicates that most learners, $113(97.4 \%)$, were Christians, who also formed the majority of those who demonstrated ethical sensitivity, 29 (96.7\%); as well as those who were ethically insensitive, 84 (97.7\%). However, the analysis revealed lack of a significant association between religious affinity and ethical sensitivity in decision-making $\left(\chi^{2}=0.000, \mathrm{df}=1 \& \rho\right.$-value $\left.=1.000\right)$; which suggests that Christians and Muslims were homogenous in terms of ethical sensitivity.

Besides, 91 (78.4\%) learners were in the third year of study, while $25(21.6 \%)$ were doing their fourth year. Among the 30 learners who made ethically sensitive decisions, $18(60.0 \%)$ were in third year, while $12(40.0 \%)$ were fourth-years. Those whose decisions were ethically insensitive $(n=86)$, consisted of $73(84.9 \%)$ learners in third year and $13(15.1 \%)$ in fourth year. Based on the cross-tabulations, the analysis revealed up to $99 \%$ chance that learners' year of study significantly associated with ethical sensitivity in decision-making $\left(\chi^{2}=10.255, \mathrm{df}=\right.$ $1 \& \rho$-value $=0.005$ ). This suggests that ethical sensitivity varied significantly with the year of study. Table 2 further indicates that $105(90.5 \%)$ learners were pursuing their studies through module 1 or the regular program, while $11(9.5 \%)$ were in module 2 and christened also known as the 'parallel programme'. Those who demonstrated ethical sensitivity $(\mathrm{n}=30)$, included $23(76.7 \%)$ learners in module 1 , and $7(23.3 \%)$ in module 2. Among those who were ethically insensitive $(\mathrm{n}=86), 82(95.3 \%)$ were in module 1 , while $4(4.7 \%)$ were in module 2. Based on this, the analysis obtained a $\chi^{2}$ value of $6.998(\mathrm{df}=1 \& \rho$-value $=0.008)$, which suggests up 
to $99 \%$ chance that learners' programme of study significantly associated with their ethical sensitivity in decision-making.

The results in Table 2 also show that 46 (39.7\%) learners studied in girls' boarding schools, 44 (37.9\%) indicated boys' boarding schools, while 14 (12.1\%) stated mixed day schools. Of the 30 learners who demonstrated ethical sensitivity, 14 (46.7\%) studied in girls' boarding schools, while $11(36.7 \%)$ went through boys' boarding schools. Among those who exhibited ethical insensitivity $(\mathrm{n}=86), 33(38.4 \%)$ studied in boys' boarding, while 32 (37.2) indicated girls' boarding schools. However, the analysis revealed lack of a significant association between the type of high school attended and ethical decision-making $\left(\chi^{2}=1.502, \mathrm{df}=3 \& \rho\right.$-value $\left.=1.682\right)$. Table 2 further shows that $61(52.6 \%)$ learners attained a mean grade of B- in the Kenya Certificate of Secondary Education (KCSE), while $26(22.4 \%)$ reported a mean grade of B. Of the 30 learners who showed ethical sensitivity, $11(36.7 \%)$ attained B+, while 10 (33.3\%) indicated B-. Among those who displayed ethical insensitivity (n=86), 51 (59.3\%) achieved B-, while 10 (11.6\%) mentioned B+. The analysis indicated a significant association between the KCSE mean grade attained and ethical sensitivity in decision-making $\left(\chi^{2}=14.384, \mathrm{df}=4 \& \rho\right.$-value $\left.=0.006\right)$.

In addition, Table 3 summarizes Chi square test results between ethical sensitivity in decision-making and various variables encapsulated by learners' professional and family profiles. The results show that ethical sensitivity in decision-making significantly associated with all the variables constituting learners' professional profile, at three levels of confidence, viz. $90 \%, 95 \%$ and $99 \%$.

Table 3. Statistical association between ethical sensitivity in decision-making and learners' profiles

\begin{tabular}{lllll}
\hline Learners' profile & Variables & \multicolumn{3}{l}{ Chi square results } \\
\cline { 3 - 5 } & & $\chi^{2}$ & $d f$ & $\rho$-value \\
\hline Professional & Employment experience & 5.446 & 1 & $0.020^{* * *}$ \\
& Subjects taught & 12.734 & 7 & $0.079^{*}$ \\
& Employment duration & 9.886 & 2 & $0.007^{* * *}$ \\
& Experience in business & 6.981 & 1 & $0.008^{* * *}$ \\
Family & Business experience duration & 5.355 & 2 & $0.024^{* *}$ \\
& Family size & 0.222 & 2 & 0.895 \\
& Position in family/birth order & 7.031 & 2 & $0.030^{* *}$ \\
& Source of high school fees & 4.999 & 4 & 0.287 \\
& Type of caregiver at home & 4.248 & 3 & 0.236 \\
\hline
\end{tabular}

Note. $*, * * * * *$ show significance at $\rho<0.1, \rho<0.05$ and $\rho<0.01$ error margins, respectively.

Regarding family profile, the results show that ethical sensitivity in decision-making is significantly associated with learners' position or order of birth in family. Learners' attributes that did not show significant association with ethical sensitivity in decision-making, were excluded from further analysis because they were less likely to add value to the relationship between the independent and dependent variables.

\subsection{Bivariate Analysis of the Context of Vignettes and Ethical Sensitivity in Decision-Making}

The context of vignettes was measured in terms of five aspects, namely, structural, operational, financial, human resource and marketing contexts. Each context was operationalised in terms of perception statements, against which learners were requested to indicate their perceptions on a five-point Likert scale, calibrated as 'agree strongly', 'agree', 'undecided', 'disagree' and 'disagree strongly'. Learners' perceptions were then cross-tabulated against ethical sensitivity in decision-making. The results are presented as follows.

The first perception statement on structural context vignettes postulated that 'vignettes enhance the ability to make ethical decisions in different structural frameworks'. The results in Table 4 show that of the 116 learners, 62 (53.4\%) agreed strongly with the statement, while 32 (27.6\%) agreed. Contrastingly, six (5.2\%) learners disagreed with the statement, while seven $(6.0 \%)$ disagreed strongly. Cumulatively, $94(81.0 \%)$ learners affirmed that vignettes enhanced the ability to make ethical decisions in different structural frameworks, while 13 (11.2\%) negated the assertion.

In relation to decision-making, of the 30 learners who demonstrated ethical sensitivity in their decisions, 10 $(33.3 \%)$ agreed with the assertion, while five (16.7\%) disagreed strongly. Among the 86 learners whose decisions were ethically insensitive, $53(61.6 \%)$ agreed strongly with the statement, while $4(4.7 \%)$ disagreed. The analysis generated a $\chi^{2}$ value of $14.023(\mathrm{df}=4 \& \rho=0.007)$, which suggests up to $99 \%$ chance that learners' ethical decision-making significantly associated with their perception about structural context vignettes.

The second statement about operational context vignettes postulated that 'vignettes develop individuals' ethical 
sensitivity regarding organizational operations'. The results in Table 4 show that $45(38.8 \%)$ learners agreed with the claim, while $38(32.8 \%)$ agreed strongly. However, five $(4.3 \%)$ learners disagreed, while three $(2.6 \%)$ disagreed strongly. Summative results show that $83(71.6 \%)$ learners affirmed the claim, while $8(6.9 \%)$ expressed contrary views. Among those whose decisions were ethically sensitive $(\mathrm{n}=30), 11(36.7 \%)$ agreed with the assertion, while three (10.0\%) disagreed strongly. Those who exhibited ethical insensitivity included 34 (39.5\%) who agreed with the statement and two (2.3\%) who disagreed. Based on this, the results suggest up to $99 \%$ chance that ethical sensitivity in decision-making significantly associated with learners' perceptions about operational context vignettes $\left(\chi^{2}=15.376, \mathrm{df}=4 \& \rho=0.004\right)$.

The third statement about financial context vignettes asserted that 'vignettes expose learners to financial standards necessary in ethical decision-making'. Table 4 shows that $52(44.8 \%)$ learners agreed strongly with the assertion, while 38 (32.8\%) agreed. Those who disagreed were $11(9.5 \%)$ learners, while three (2.6\%) expressed strong disagreement. Cumulatively, 90 (77.6\%) learners affirmed that vignettes expose learners to financial standards necessary in ethical decision-making, while $14(12.1 \%)$ refuted the assertion. Among those who showed ethical sensitivity in their decisions $(\mathrm{n}=30), 12(40.0 \%)$ agreed strongly with the assertion, while seven $(23.3 \%)$ agreed. Those whose decisions were ethically insensitive $(n=86)$, included $40(46.5 \%)$ learners who agreed strongly with the assertion and $32(37.2 \%)$ who agreed. The analysis revealed up to $95 \%$ chance that ethical sensitivity in decision-making significantly associated with learners' perceptions about financial context vignettes $\left(\chi^{2}=13.017, \mathrm{df}=4 \& \rho\right.$-value $\left.=0.011\right)$.

Table 4. Perceptions about the context of vignettes and ethical sensitivity in decision-making

\begin{tabular}{|c|c|c|c|c|c|c|c|c|c|}
\hline \multirow[t]{3}{*}{ Contexts of vignettes in business education } & \multicolumn{6}{|c|}{ Ethical Sensitivity in Decision-Making } & \multicolumn{3}{|c|}{ Chi square results } \\
\hline & \multicolumn{2}{|c|}{ Ethically sensitive } & \multicolumn{2}{|c|}{ Ethically insensitive } & \multicolumn{2}{|l|}{ Total } & \multirow{2}{*}{$\chi^{2}$} & \multirow[b]{2}{*}{$d f$} & \multirow[b]{2}{*}{$\rho$-value } \\
\hline & Freq & Percent & Freq & Percent & Freq & Percent & & & \\
\hline \multicolumn{10}{|l|}{$\begin{array}{l}\text { Enhance ability to make ethical decisions in } \\
\text { different structural frameworks }\end{array}$} \\
\hline Agree strongly & 9 & 30.0 & 53 & 61.6 & 62 & 53.4 & & & \\
\hline Agree & 10 & 33.3 & 22 & 25.6 & 32 & 27.6 & & & \\
\hline Undecided & 4 & 13.3 & 5 & 5.8 & 9 & 7.8 & 14.023 & 4 & $0.007^{* * *}$ \\
\hline Disagree & 2 & 6.7 & 4 & 4.7 & 6 & 5.2 & & & \\
\hline Disagree strongly & 5 & 16.7 & 2 & 2.3 & 7 & 6.0 & & & \\
\hline Total & 30 & 100.0 & 86 & 100.0 & 116 & 100.0 & & & \\
\hline \multicolumn{10}{|l|}{$\begin{array}{l}\text { Develop individual's ethical sensitivity } \\
\text { regarding organizational operations }\end{array}$} \\
\hline Agree strongly & 5 & 16.7 & 33 & 38.4 & 38 & 32.8 & & & \\
\hline Agree & 11 & 36.7 & 34 & 39.5 & 45 & 38.8 & & & \\
\hline Undecided & 8 & 26.7 & 17 & 19.8 & 25 & 21.6 & 15.376 & 4 & $0.004^{* * *}$ \\
\hline Disagree & 3 & 10.0 & 2 & 2.3 & 5 & 4.3 & & & \\
\hline Disagree strongly & 3 & 10.0 & 0 & 0.0 & 3 & 2.6 & & & \\
\hline Total & 30 & 100.0 & 86 & 100.0 & 116 & 100.0 & & & \\
\hline \multicolumn{10}{|l|}{$\begin{array}{l}\text { Expose learners to financial standards } \\
\text { necessary in ethical decision-making }\end{array}$} \\
\hline Agreed strongly & 12 & 40.0 & 40 & 46.5 & 52 & 44.8 & & & \\
\hline Agree & 6 & 20.0 & 32 & 37.2 & 38 & 32.8 & & & \\
\hline Undecided & 3 & 10.0 & 9 & 10.5 & 12 & 10.3 & 13.017 & 4 & $0.011^{* *}$ \\
\hline Disagree & 7 & 23.3 & 4 & 4.7 & 11 & 9.5 & & & \\
\hline Disagree strongly & 2 & 6.7 & 1 & 1.2 & 3 & 2.6 & & & \\
\hline Total & 30 & 100.0 & 86 & 100.0 & 116 & 100.0 & & & \\
\hline \multicolumn{10}{|l|}{$\begin{array}{l}\text { Instill human resource management idealism } \\
\text { and relativism in learners }\end{array}$} \\
\hline Agree strongly & 6 & 20.0 & 21 & 24.4 & 27 & 23.3 & & & \\
\hline Agree & 11 & 36.7 & 48 & 55.8 & 59 & 50.9 & & & \\
\hline Undecided & 6 & 20.0 & 7 & 8.1 & 13 & 11.2 & 8.318 & 4 & $0.081^{*}$ \\
\hline Disagree & 6 & 20.0 & 6 & 7.0 & 12 & 10.3 & & & \\
\hline Disagree strongly & 1 & 3.3 & 4 & 4.7 & 5 & 4.3 & & & \\
\hline Total & 30 & 100.0 & 86 & 100.0 & 116 & 100.0 & & & \\
\hline \multicolumn{10}{|l|}{$\begin{array}{l}\text { Expose learners to marketing ethical related } \\
\text { concepts and contents }\end{array}$} \\
\hline Agree strongly & 17 & 56.7 & 50 & 58.1 & 67 & 57.8 & & & \\
\hline Agree & 4 & 13.3 & 28 & 32.6 & 32 & 27.6 & & & \\
\hline Undecided & 4 & 13.3 & 0 & 0.0 & 4 & 3.4 & 15.684 & 4 & $0.003^{* * *}$ \\
\hline Disagree & 3 & 10.0 & 4 & 4.7 & 7 & 6.0 & & & \\
\hline Disagree strongly & 2 & 6.7 & 4 & 4.7 & 6 & 5.2 & & & \\
\hline Total & 30 & 100.0 & 86 & 100.0 & 116 & 100.0 & & & \\
\hline
\end{tabular}

Note. ${ }^{*},{ }^{* *}, * * *$ show significance at $\rho<0.1, \rho<0.05$ and $\rho<0.01$ error margins, respectively. 
The fourth statement about human resource context vignettes suggested that 'vignettes instill human resource management idealism and relativism in learners'. Table 4 shows that $59(50.0 \%)$ learners agreed with the assertion, while $27(23.3 \%)$ indicated strong agreement. However, 12 (10.3\%) learners disagreed, while five (4.3\%) expressed strong disagreement. Collectively, 86 (74.1\%) learners confirmed the assertion, while 17 (14.6\%) refuted it. Besides, those whose decisions were ethically sensitive $(\mathrm{n}=30)$, included $11(36.7 \%)$ learners who agreed with the statement and six (20.0\%) agreed strongly; while another six $(20.0 \%)$ disagreed. Among the 86 learners whose decisions were ethically insensitive, 48 (55.8\%) agreed with the statement, while $21(23.3 \%)$ agreed strongly. The analysis obtained a $\chi^{2}$ value of $8.318(\mathrm{df}=4 \& \rho=0.081)$, which suggests up to $90 \%$ chance that ethical sensitivity in decision-making significantly associated with learners' perception concerning human resource context vignettes.

The fifth statement regarding marketing context vignettes indicated that 'vignettes expose learners to marketing ethical related concepts and contents'. As indicated in Table 4, 67 (57.8\%) learners agreed strongly with the claim, while $32(27.6 \%)$ agreed. Those who disagreed with the statement were seven $(6.0 \%)$, while six (5.2\%) indicated strong disagreement. Cumulatively, 99 (85.3\%) learners affirmed the assertion, while $13(11.2 \%)$ refuted it. Among those whose decisions were ethically sensitive $(\mathrm{n}=30), 17(56.7 \%)$ agreed strongly with the statement, while four (13.3\%) agreed. Those who showed ethical insensitivity in their decisions $(\mathrm{n}=86)$ included $50(58.1 \%)$ learners who agreed strongly with the claim and $28(32.6 \%)$ who agreed. The analysis revealed a significant association between ethical sensitivity in decision-making and learners' perceptions about marketing context vignettes $\left(\chi^{2}=15.684, \mathrm{df}=4 \& \rho\right.$-value $\left.=0.003\right)$.

Bivariate results were aggregated to determine learners' optimal perceptions regarding relationship between the context of vignettes and ethical sensitivity in decision-making. The aggregated perceptions were also measured using the five-point Likert scale, also ordered as 'agree strongly', 'agree', 'undecided', 'disagree' and 'disagree strongly'. The results in Figure 3 show that of the 116 learners, 50 (43.1\%) agreed that the context of vignettes influenced learners' ethical sensitivity in decision-making. Among those who demonstrated ethical sensitivity in their decisions $(\mathrm{n}=30), 16(53.3 \%)$ agreed with the assertion, while two $(6.7 \%)$ disagreed. Those whose decisions were ethically insensitive $(\mathrm{n}=86)$ included $34(39.5 \%)$ learners who agreed with the assertion, 19 (22.1\%) who agreed strongly, and 14 (16.3\%) who disagreed strongly.

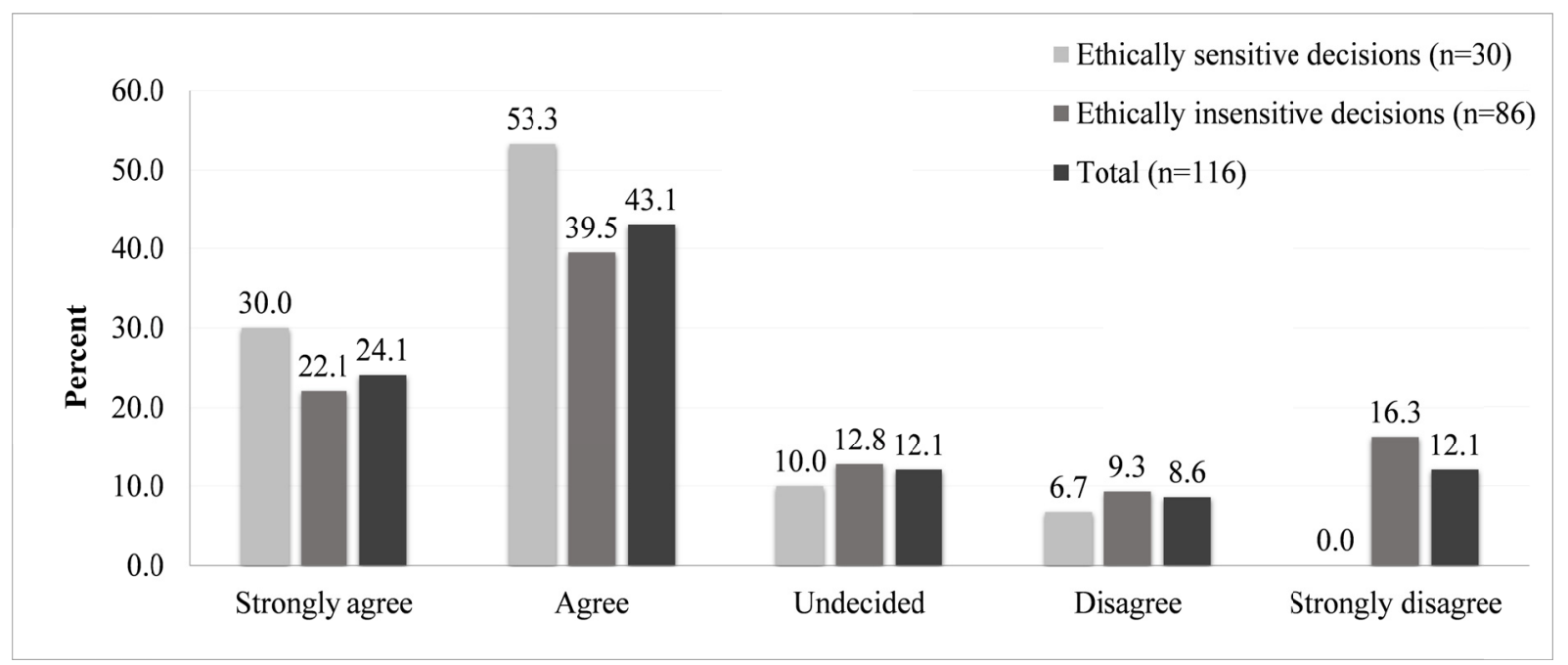

Figure 3. Aggregated views on the nexus between context of vignettes \& ethical sensitivity in decision-making

The analysis generated a Spearman's rank correlation coefficient $\left(r_{s}\right)$ of $-0.222(\rho$-value $=0.017)$, which suggests up to $95 \%$ chance that learners' aggregated perceptions regarding the context of vignettes significantly correlated with their ethical sensitivity in decision-making. Consequently, the null hypothesis stating that there is no significant correlation between the context of vignettes and ethical sensitivity in decision-making was rejected for being inconsistent with the results.

\subsection{Influence of the Context of Vignette on Ethical Sensitivity in Decision-Making: Multivariate Analysis}

The aggregated perception about the context of vignettes (independent variable) was incorporated in the binary 
logistic regression model so as to determine its influence on ethical sensitivity in decision-making (dependent variable). Learners' background profile attributes were included in the model as moderating factors. Collinearity diagnostics revealed signs of confounding connections between learners' experience in business and duration of business experience. In this regard, duration of business experience was excluded from the regression model in accordance with the principles of collinearity analysis. The results in Table 5 show that learners who agreed strongly that the context of vignettes influences their ethical sensitivity in decision-making were about 3.9 times as likely to make ethically sensitive decisions as their colleagues who expressed a strong disagreement ( $\rho$-value $=0.004, \beta=1.355, \mathrm{OR}=3.877$, C.I. $=2.087-7.202$ ). The results suggest up to $99 \%$ chance that variation between the two groups in terms of the odds of making ethically sensitive decisions was statistically significant.

Table 5. Results of the adjusted logistic regression model

\begin{tabular}{|c|c|c|c|c|c|c|c|c|}
\hline \multirow[t]{2}{*}{ I. Independent Covariate } & \multirow[t]{2}{*}{ B } & \multirow[t]{2}{*}{ SE } & \multirow[t]{2}{*}{ Wald } & \multirow[t]{2}{*}{ df } & \multirow[t]{2}{*}{ sig. } & \multirow[t]{2}{*}{$\operatorname{EXP}(B)$} & \multicolumn{2}{|c|}{ 95\% C.I. for EXP(B) } \\
\hline & & & & & & & Lower & Upper \\
\hline Context of vignettes & & & 24.958 & 4 & $0.000^{* * * *}$ & & & \\
\hline Agreed strongly & 1.355 & 0.316 & 18.387 & 1 & $0.004^{* * *}$ & 3.877 & 2.087 & 7.202 \\
\hline Agree & 0.854 & 0.269 & 10.079 & 1 & $0.025^{* *}$ & 2.349 & 1.386 & 3.151 \\
\hline Undecided & 0.565 & 0.199 & 8.061 & 1 & $0.027^{* *}$ & 1.759 & 1.191 & 2.599 \\
\hline Disagree & 0.152 & 0.281 & 0.293 & 1 & 0.236 & 1.164 & 0.671 & 2.019 \\
\hline Disagree strongly (RC) & 1.000 & 1.000 & 1.000 & 1.000 & 1.000 & 1.000 & 1.000 & 1.000 \\
\hline \multicolumn{9}{|l|}{ II. Moderating Covariates } \\
\hline Age & & & 13.117 & 2 & $0.018^{* *}$ & & & \\
\hline$<23$ years & -1.852 & 0.615 & 9.068 & 1 & 0.177 & 0.157 & 0.047 & 0.524 \\
\hline $23-25$ years & -0.938 & 0.316 & 8.811 & 1 & 0.519 & 0.391 & 0.211 & 0.727 \\
\hline 26 years $+(\mathrm{RC})$ & 1.000 & 1.000 & 1.000 & 1.000 & 1.000 & 1.000 & 1.000 & 1.000 \\
\hline Academic year & & & 11.008 & 1 & $0.020^{* *}$ & & & \\
\hline Third year & -2.084 & 0.698 & 8.914 & 1 & 0.633 & 0.124 & 0.032 & 0.489 \\
\hline Fourth year (RC) & 1.000 & 1.000 & 1.000 & 1.000 & 1.000 & 1.000 & 1.000 & 1.000 \\
\hline Program module & & & 6.214 & 1 & $0.021^{* *}$ & & & \\
\hline Module 1 & 0.625 & 0.276 & 5.128 & 1 & $0.035^{* *}$ & 1.868 & 1.088 & 2.209 \\
\hline Module 2 (RC) & 1.000 & 1.000 & 1.000 & 1.000 & 1.000 & 1.000 & 1.000 & 1.000 \\
\hline KCSE grade & & & 6.828 & 4 & & & & \\
\hline A- & 0.773 & 0.417 & 3.436 & 1 & $0.027^{* *}$ & 2.166 & 0.957 & 3.905 \\
\hline $\mathrm{B}+$ & 0.457 & 0.436 & 1.099 & 1 & $0.063^{*}$ & 1.579 & 0.672 & 2.712 \\
\hline B & 0.230 & 0.470 & 0.239 & 1 & 0.118 & 1.259 & 0.501 & 2.162 \\
\hline B- & 0.522 & 0.465 & 1.260 & 1 & $0.052^{*}$ & 1.685 & 0.677 & 2.193 \\
\hline $\mathrm{C}+(\mathrm{RC})$ & 1.000 & 1.000 & 1.000 & 1.000 & 1.000 & 1.000 & 1.000 & 1.000 \\
\hline Employment experience & & & 1.992 & 1 & $0.091^{*}$ & & & \\
\hline Yes & 0.305 & 0.424 & 0.517 & 1 & 0.106 & 1.357 & 0.591 & 2.114 \\
\hline No (RC) & 1.000 & 1.000 & 1.000 & 1.000 & 1.000 & 1.000 & 1.000 & 1.000 \\
\hline Experience in business & & & 1.656 & 1 & $0.088^{*}$ & & & \\
\hline Yes & 0.278 & 0.747 & 0.138 & 1 & 0.109 & 1.320 & 0.305 & 2.709 \\
\hline No (RC) & 1.000 & 1.000 & 1.000 & 1.000 & 1.000 & 1.000 & 1.000 & 1.000 \\
\hline Position in family & & & 7.199 & 2 & $0.031^{* *}$ & & & \\
\hline$<4$ th position & 0.605 & 0.276 & 4.805 & 1 & $0.039^{* *}$ & 1.831 & 1.066 & 3.145 \\
\hline 4th-6th position & 0.368 & 0.335 & 1.207 & 1 & $0.078^{*}$ & 1.445 & 0.749 & 2.786 \\
\hline$>6$ th position (RC) & 1.000 & 1.000 & 1.000 & 1.000 & 1.000 & 1.000 & 1.000 & 1.000 \\
\hline Constant & 4.270 & 0.695 & $\mathbf{3 7 . 7 4 7}$ & 1 & $0.000^{* * * *}$ & 71.522 & 38.316 & 99.624 \\
\hline
\end{tabular}

Note. ${ }^{*}, * * *$ show significance at $\rho<0.1, \rho<0.05$ and $\rho<0.01$ error margins, respectively; $\mathrm{RC}=$ Reference Category.

The results further show that learners who agreed that the context of vignettes influences their ethical sensitivity in decision-making had about 2.3 times the odds of making ethically sensitive decisions as their colleagues who indicted a strong disagreement ( $\rho$-value $=0.025, \beta=0.854$, $\mathrm{OR}=2.349$, C.I. $=1.386-3.151$ ). In this case, the results suggest up to $95 \%$ chance that the two groups were significantly different in terms of the odds of making ethically sensitive decisions. Notably, the more the learners agreed that the context of vignettes influences their ethical sensitivity in decision-making, the higher the chances of them making ethically sensitive decisions, and vice-versa. This brings up the need to teach learners how to understand the contexts in which vignettes are applied within business in order to improve the odds of them making ethically sensitive decisions. 
In relation to this, qualitative results indicated that each context of a business setting is unique in terms of core functions and experiences. Participants explained that experiences of the financial context, for example, are different from those of the operational context because of the divergence of their functions. More overtly, the frequency of situations demanding ethical decision-making varies across the contexts, depending on the sensitivity of their functions. In this regard, some participants noted that an employee handling petty cash daily, experiences relatively more scenarios that demand ethical decisions than one assuming operational functions. In the words of a participant, "...the management of financial resources is very sensitive..., it demands a high level of ethical sensitivity in order to make ethical decisions. There are many temptations around handling cash in an organization." Participants further identified the structural context as an area prone to ethical issues that often conflict with organizational strategic orientation.

Qualitative results obtained from key informant interviews (KIIs) and focus group discussions (FDGs) further revealed that most instructors use vignettes inadvertently to teach business ethics, because vignettes were yet to be integrated in the curriculum as instructional resources. Consequently, the use of vignettes to teach business ethics was mainly a personal initiative. Participants observed that even though some course materials contain case studies and stories, most instructors prefer to develop and apply their own vignettes. The challenge is how to align such vignettes to the various ethical contexts in an organization. As noted by one lecturer, "...the concept of vignettes is new, so most instructors don't have detailed knowledge of how they should be applied to various ethical contexts in a business setting. Because of this, there is no telling whether the case studies applied by instructors in their lessons are appropriate for various ethical contexts. Even though most instructors are innovative, there is need for detailed training on the application of vignettes to explain ethical issues in each context of business, be it leadership, finance, marketing, product development or any other area."

\section{Discussion}

The study was expected to influence pedagogical reforms and management interventions intended to improve experiential teaching of business ethics at the Department. The information was further expected to support policy discourses at various levels, intended to improve resourcing of the pedagogical reforms, besides spurring more research on the use of vignettes and learners' ethical sensitivity in decision-making in Kenya and elsewhere.

Most learners, $99(85.3 \%)$, affirmed that the marketing context vignettes enhanced their ethical sensitivity in decision-making; followed by 94 (81.0\%) learners who cited structural context vignettes; and 90 (77.6\%) who mentioned financial context vignettes. Besides, 86 (74.1\%) learners stated human resource context vignettes; while operational context vignettes were cited by $83(71.6 \%)$ learners. This suggests that marketing context vignettes influenced most learners' ethical sensitivity in decision-making, while operational context vignettes influenced the least proportion of learners. Consequently, the effectiveness of vignettes as instructional resources in experiential learning varies with the contexts within which they are applied.

Learners' aggregated perceptions about the context of vignettes significantly correlated with ethical sensitivity in decision-making, thereby prompting rejection of the null hypothesis postulating lack of a significant correlation between the context of vignettes and ethical sensitivity in decision-making. In addition, learners who agreed strongly that the context of vignettes influences their ethical sensitivity in decision-making had about 3.9 times the odds of making ethically sensitive decisions as their colleagues who disagreed strongly. Besides, those who agreed that the context of vignettes influenced their ethical sensitivity in decision-making had about 2.3 times the odds of making ethically sensitive decisions as their colleagues who disagreed strongly. In each scenario, variation between the two groups, regarding the odds of making ethically sensitive decisions, was statistically significant. This implies that the more the learners appreciated that the context of vignettes influenced ethical sensitivity in decision-making, the higher the odds of them making ethically sensitive decisions, and vice-versa.

As observed by Dretske (2000), perception and knowledge are connected concepts. As the level of knowledge about a phenomenon improves, perceptions change in a proportionate measure, either positively or negatively depending on social acceptance of the phenomenon in question. Regardless of the direction of change, improving knowledge enables one to develop informed perceptions. Within the milieu of this study, improving learners' knowledge about the context of vignettes is vital for improving their ethical sensitivity and propensity to make ethical decisions. Furthermore, improving learners' knowledge of the context of vignettes is vital for maintaining ethical sensitivity, which is elemental to ethical decision-making.

Moreover, participants identified structural, financial and marketing context vignettes as the key aspects influencing learners' ethical sensitivity in decision-making. Each context is unique in terms core functions, ethical sensitivity of the core functions and experiences demanding ethical decision-making. Instructional 
materials for experiential teaching should identify and profile such contexts based on the ethical sensitivity of their functions and frequency of scenarios, demanding ethical sensitivity in decision-making. In this regard, contexts with varied experiences and highly sensitive functions should be considered for inclusion in instructional approaches to improve the quality of experiential teaching of business ethics. The richer the instructional approaches, the better the odds of learners making ethically sensitive decisions. However, it is worth noting that the richness of contextual units varies from one organization to the other. Thus, each context requires tailor-made vignettes to effectively equip learners with skills for ethical sensitivity in decision-making.

\section{Conclusion}

Most instructors use vignettes inadvertently because this approach has not been integrated in the course's instructional design. Additionally, most instructors lack in-depth knowledge on the application of vignettes in experiential teaching. Although some instructors created and applied vignettes out of innovation, participants could not tell the extent to which such vignettes aligned with Business Education course content and with real work experiences under each context. This implies that instructors at the Department should undergo proper training on the application of vignettes in each context of business for appropriate application in the course unit.

\section{Acknowledgments}

We thank the UoN for granting the first author the opportunity to pursue doctoral studies in Business Education, and for assigning the second and third authors as supervisors. We further thank the Department for permitting the first author to source information from their undergraduate learners. We remain indebted to all the participants who provided the requisite information. Lastly, we thank Thomas Oriwo, Tom Odhiambo and Noah Oyembo for providing research assistance.

\section{References}

Allibaih, M., \& Khan, L. M. (2015). Weaving Together Peer Assessment, Audios and Medical Vignettes in Teaching Medical Terms. International Journal of Medical Education, 6, 172-178. https://doi.org/10.5116/ijme.564a.2ed6

Ashley, D., \& Orenstein, D. M. (2005). Sociological Theory: Classical Statements (6th ed.). Boston, MA: Pearson Education.

Barczyk, C. C., \& Duncan, G. D. (2012). Social Networking Media: An Approach for the Teaching of International Business. Journal of Teaching in International Business, 23(2), 98-122. https://doi.org/10.1080/08975930.2012.718703

Best, J. W., \& Khan, J. V. (2004). Research in Education (7th ed.). New Delhi: Prentice Hall of India.

Bryman, A., \& Cramer, D. (1998). Quantitative Data Analysis with SPSS for Windows: A Guide for Social Scientists. London: Routledge.

Butterfield, K., Treviño, L., \& Weaver, G. (2000). Moral Awareness in Business Organizations: Influences of Issue-Related and Social Context Factors. Human Relations, 53(7), 981-1018. https://doi.org/10.1177/0018726700537004

Carroll, A. B. (1990). Principles of Business Ethics: Their Role in Decision Making and an Initial Consensus. Management Decision, 28(8), 20-24. https://doi.org/10.1108/00251749010006032

Cochran, W. G. (1963). Sampling Techniques (2nd ed.). New York: John Wiley and Sons, Inc.

Davis, S., DeZoort, F. T., \& Kopp, L. S. (2006). The Effect of Obedience Pressure and Perceived Responsibility on Management Accountants' Creation of Budgetary Slack. Behavioral Research in Accounting, 18(1), 19-35. https://doi.org/10.2308/bria.2006.18.1.19

Dench, S., Iphofen, R., \& Huws, U. (2004). An EU Code of Ethics for Socio-Economic Research Report. London: Institute for Employment Studies.

Detert, J., Treviño, L., \& Sweitzer, V. (2008). Moral Disengagement in Ethical Decision Making: A Study of Antecedents and Outcomes. Journal of Applied Psychology, 93(2), 374-391. https://doi.org/10.1037/0021-9010.93.2.374

Dretske, F. (2000). Entitlement: Epistemic Rights without Epistemic Duties? Philosophy a Phenomenological Research, 60(3), 532-537. https://doi.org/10.2307/2653817

Easterby-Smith, M., Thorpe, R., \& Lowe, A. (1991). The Philosophy of Research Design. Management Research: An Introduction. London: Sage Publications. 
Effelsberg, D., Solga, M., \& Gurt, J. (2014). Transformational Leadership and Follower's Unethical Behavior for the Benefit of the Company: A Two-Study Investigation. Journal of Business Ethics, 120(1), 81-93. https://doi.org/10.1007/s10551-013-1644-z

Emanuel, V., \& Cross, V. (2012). Using Vignettes to Teach Stroke Care. Nursing Times, 108(9), 20-22.

Gray, D., Griffin, C., \& Nasta, T. (2005). Training to Teach in Further and Adult Education (2nd ed.). Abingdon, UK: Nelson Thornes.

Gronhoj, A., \& Bech-Larsen, T. (2010). Using Vignettes to Study Family Consumption Processes. Psychology and Marketing, 27(5), 1-34. https://doi.org/10.1002/mar.20338

Guzak, J. R., \& Hargrove, M. B. (2011). The Role of Intuition in Ethical Decision-Making. In M. Sinclair (Ed.), Handbook of Intuition Research (pp. 97-108). Edward Elgar: Cheltenham, UK.

Harland, T. (2014). Learning About Case Study Methodology to Research Higher Education. Higher Education Research and Development, 33(6), 1113-1122. https://doi.org/10.1080/07294360.2014.911253

Hativa, N. (2000). Teaching for Effective Learning in Higher Education. Dordrecht: Springer Netherlands. https://doi.org/10.1007/978-94-010-0902-7

Hill, B. (2019). Financial Aspects of Business. Retrieved April 11, 2020, from https://smallbusiness.chron.com/financial-aspects-business-4068.html

Kidwell, R. E., \& Valentine, S. R. (2009). Positive Group Context, Work Attitudes and Organizational Misbehavior: The Case of Withholding Job Effort. Journal of Business Ethics, 86(1), 15-28. https://doi.org/10.1007/s10551-008-9790-4

Kolb, A. Y., \& Kolb, D. A. (2017). Experiential Learning Theory as a Guide for Experiential Educators in Higher Education. ELTHE: A Journal for Engaged Educators, 1(1), 7-44.

Kothari, C. R. (2010). Research Methodology, Methods and Techniques (2nd ed.). New Delhi: New Age International Publishers.

Kozak, M., \& Zieli'nski, A. (2005). Sample Allocation between Domains and Strata. International Journal of Applied Mathematics and Statistics, 3, 19-40.

Manolis, C., Burns, D. J., Assudani, R., \& Chinta, R. (2012). Assessing Experiential Learning Styles: A Methodological Reconstruction and Validation of the Kolb Learning Style Inventory. Learning and Individual Differences, 23, 44-52. https://doi.org/10.1016/j.lindif.2012.10.009

March, J. (2010). The Ambiguities of Experience. Ithaca: Cornell University Press.

Marques, P. A., \& Azevedo-Pereira, J. J. (2009). Ethical Ideology and Ethical Judgments in the Portuguese Accounting Profession. Journal of Business Ethics, 86(2), 227-242. https://doi.org/10.1007/s10551-008-9845-6

Mazanec, J. A. (2005). New Methodology for Analyzing Competitive Positions: A Demonstration Study of Travelers' Attitude toward their Modes of Transport. Tourism Analysis, 9(1), 1-10. https://doi.org/10.3727/108354205789807283

McLeod, S. A. (2017). Kolb-Learning Styles. Retrieved June 23, 2018, from www.simplypsychology.org/learning-kolb.html

McNamara, A., Smith, J., \& Murphy-Hill, E. (2018). Does ACM's Code of Ethics Change Ethical Decision-Making in Software Development? A Paper Presented during the 26th ACM Joint European Software Engineering Conference and Symposium on the Foundations of Software Engineering (ESEC/FSE'18), November 4-9, 2018, Lake Buena Vista, FL, USA. https://doi.org/10.1145/3236024.3264833

Myers, J. L., \& Well, A. D. (2003). Research Design and Statistical Analysis. Hillsdale, NJ: Lawrence Erlbaum Associates. https://doi.org/10.4324/9781410607034

Nachmias, C. F., \& Nachmias, D. (1996). Research Methodology in Social Sciences (5th ed.) London: St. Martin's Press.

Odundo, A. P., \& Gunga, S. O. (2013). The Effects of Application on Institutional Methods on Learner Achievement in Business in Secondary Schools in Kenya. International Journal of Education and Research, $1(5), 1-22$. 
Oluoch, P. M., Odundo, P. A., \& Mwangi, J. (2019). Value of Vignette Contexts in Ethical Decision Making Among Business Education Students at the University of Nairobi. Imperial Journal of Interdisciplinary Research, 5(2), 66-76.

Oluoch, P. M., Odundo, P. A., Mwangi, J., \& Oyier, C. R. (2018). Effects of Vignettes Types in Enhancing Ethical Decision among Business Education Students. International Journal of Business and Management, 13(10), 249-258. https://doi.org/10.5539/ijbm.v13n10p249

Omwenga, E. I. (2006). Pedagogical Issues and e-Learning Cases: Integrating ICTs into Teaching and Learning Process. Nairobi: School of Computing and Informatics.

Pan, Y., \& Sparks, J. R. (2012). Predictors, Consequence, and Measurement of Ethical Judgments: Review and Meta-analysis. Journal of Business Research, 65(1), 84-91. https://doi.org/10.1016/j.jbusres.2011.02.002

Petrina, S. (2004). Curriculum and Instruction for Technology Teachers. Retrieved April 22, 2020, from https://www.semanticscholar.org

Polit, D. F., \& Beck, C. T. (2006). The Content Validity Index: Are You Sure You Know What's Being Reported? Critique and Recommendations. Research in Nursing \& Health, 29(5). 489-497. https://doi.org/10.1002/nur.20147

Pont, B., Nuschew, D., \& Moorman, H. (2008). Improving School Leadership (Vol. 1: Policy and Practice). Retrieved from http://www.oecd.org/education/school/44374889.pdf

Racelis, A. (2015). Integrating Ethics in Finance and Accounting Courses using Ethical Banks as Vignette. International Journal of Business Ethics in Developing Economies, 4(1), 16-23. https://doi.org/10.21863/ijbede/2015.4.1.001

Rindfleisch, A., Malter, A. J., Ganesan, S., \& Moorman, C. (2008). Cross-sectional Versus Longitudinal Survey Research. Journal of Marketing Research, 45(3), 1-23. https://doi.org/10.1509/jmkr.45.3.261

Ritter, N. L. (2010). Understanding a Widely Misunderstood Statistic: Cronbach's Alpha. A Paper Presented at the Annual Meeting of the Southwest Educational Research Association, New Orleans, February 18, 2010.

Sarfo, F. K. (2007). Educational Technology. Accra: Wilas Press.

University of Nairobi. (2017). Latest News. Retrieved May 8, 2020, from http://www.uonbi.ac.ke

University of Nairobi. (2018). Annual Report 2018. Retrieved May 8, 2020, from http://erepository.uonbi.ac.ke/handle/11295/106525

Van Summeren, R. (2018). The Influence of Organizational Structure on Ethical Decision-Making: A Qualitative Study into the Effects of Decentralization and Formalization on Moral Awareness. Thesis Submitted to Radboud Universiteit Nijmegen, Netherlands. Retrieved from https://s3-eu-central-1.amazonaws.com/viisi/app/uploads/20190214150813/Rik-van-Summeren-The-Influe nce-of-Organizational-Structure-on-Ethical-Decision-Making.pdf

Weiss, J. W. (2014). Business Ethics (6th ed., A Stakeholder and Issues Management Approach). Oakland, CA: Berrett-Koehler.

Wong, P. W. (2014). A Snapshot on Qualitative Research Methods. Educational Research and Reviews, 9(5), 130-140. https://doi.org/10.5897/ERR2014.1801

Woods, C. (2014). Functional Structure of an Organization: Advantages, Disadvantages \& Example. Retrieved September 6, 2014, from https://study.com/academy/lesson/functional-structure-of-an-organization-advantages-disadvantages-examp le.html

Wuensch, K. L. (2006). Logistic Regression with SPSS. Retrieved September 11, 2018, from http://core.ecu.edu/psyc/wuenschk/spss/logistic.sav 


\section{Appendix A}

\section{Self-Administered Questionnaire for Learners}

\section{A. BACKGROUND INFORMATION}

Please Tick $(\vee)$ to mark the answer that most closely resembles your position

1.1 Gender
1.2 Year of Study Academi
1.3 KCSE Grade
1.4 Programme of Study
1.5 Teaching Subjects
1.6 County
1.7 Sub-County
1.8 High School Attended

1.9 Age

1.10 Business experience

1.11 Business experience duration

1.12 Employment/Internship history

1.13 Employment/Internship history duration

1.14 Family Size

1.15 Your position in the family

1.16 Ethnicity

1.17 Religion

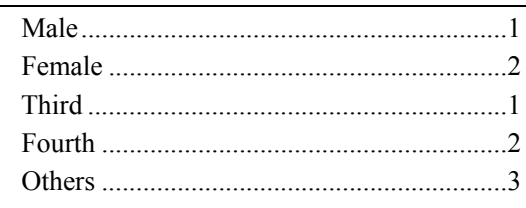

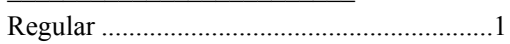

Parallel/Module II ...........................................2

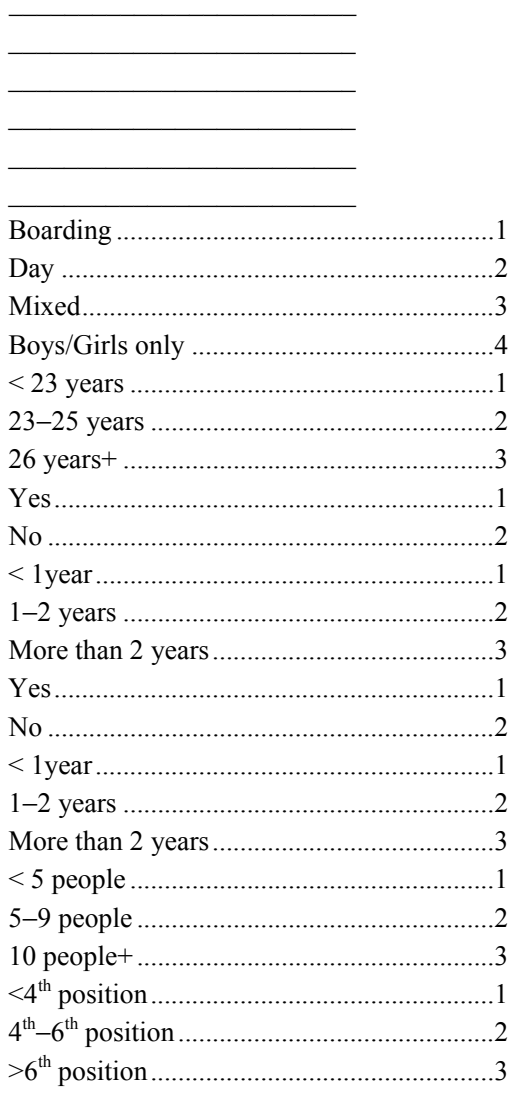

\section{B. ADOPTION OF VIGNETTES INSTRUCTIONAL METHOD AND ETHICAL SENSITIVITY IN} DECISION-MAKING

Indicate the extent to which you agree or disagree with the following aspects of vignettes instructional method' adoption in teaching business ethics. Please tick the most appropriate space under each code.

\section{1-Strongly Agree, 2-Agree, 3 - Uncertain, 4 - Disagree, and 5- Strongly Disagree}

\begin{tabular}{|c|c|c|c|c|c|c|}
\hline \multicolumn{2}{|r|}{ Usefulness of vignettes instructional method in business contexts } & 1 & 2 & 3 & 4 & 5 \\
\hline 1.1 & Enhance ability to make ethical decisions in different leadership frameworks & & & & & \\
\hline 1.2 & Develop individual ethical sensitivity in regard to organizational operations & & & & & \\
\hline 1.3 & Expose learners to financial standards necessary in ethical decision-making & & & & & \\
\hline 1.4 & Instill human resource management idealism and relativism in learners & & & & & \\
\hline 1.5 & Expose learners to marketing ethical related concepts and contents & & & & & \\
\hline
\end{tabular}




\section{VIGNETTE AND ETHICAL DECISION-MAKING}

The following vignette requires different ethical behaviors acquired from a set of skills from learning business ethics. You are required to respond to questions posed after carefully reading the vignette.

VIGNETTE: You and Lisa are Business studies educators at Kitenge High School, a mid-sized boy boarding school. Your department has recently completed setting the end of term Business studies exams and your head of department has handed it to with the request that you hand it over to the exam office. You and Lisa are working late that night when you receive a call from the Principal, who asks you to immediately forward him a copy of the draft Business studies end of term exam. When you locate the copy, you discover that your head of department had sealed it and written "Final Copy, Confidential" on the envelope. Your head of department is out of the country attending a seminar and you know it would be impossible to locate him for consultation. The Principal has a son in your class and the boy is always top of his class.

How would you handle the principal's request?

\subsection{Select one response Yes/No}

\begin{tabular}{|c|c|c|c|}
\hline & Yes & No & Comment on your response \\
\hline \multicolumn{4}{|l|}{ It is an ethical responsibility to accept principal's request } \\
\hline \multicolumn{4}{|l|}{ Was the principal's request professional } \\
\hline \multicolumn{4}{|l|}{ Is there confidentiality risk in accepting principal's request } \\
\hline \multicolumn{4}{|l|}{ Honesty } \\
\hline Should respect for authority by accepting principal's request & & & \\
\hline
\end{tabular}

\subsection{Please rate the importance of each issue in making your decisions.}

1 = Very important 2 = Important 3 = Indifferent 4 = Unimportant $5=$ Very Unimportant

\begin{tabular}{|c|c|c|}
\hline CONSIDERATION IN MAKING DECISIONS & Score & Comments \\
\hline \multicolumn{3}{|l|}{ Taking personal responsibility } \\
\hline \multicolumn{3}{|l|}{ Acting with professionalism } \\
\hline \multicolumn{3}{|l|}{ Maintaining confidentiality } \\
\hline \multicolumn{3}{|l|}{ Upholding honesty } \\
\hline Showing respect for legitimate authority & & \\
\hline
\end{tabular}

\section{Copyrights}

Copyright for this article is retained by the author, with first publication rights granted to the journal.

This is an open-access article distributed under the terms and conditions of the Creative Commons Attribution license (http://creativecommons.org/licenses/by/4.0/). 